\title{
EDITORIAL
}

\section{LA INVESTIGACIÓN: \\ REQUISITO PARA EL AVANCE DE LA CALIDAD EN LAS UNIVERSIDADES PERUANAS}

Este fin de año la Superintendencia Nacional de Educación Superior Universitaria (SUNEDU) deberá concluir el proceso de licenciamiento de las universidades peruanas que faltan; ya quedan pocas, y esto representa un reto muy grande y difícil para las universidades pequeñas, pero también implica la necesidad de un gran despliegue intelectual, económico y, sobre todo, se precisa del comprometido esfuerzo de todas las autoridades y comunidad universitaria de cada una de estas casas superiores de estudios por lograr el ansiado licenciamiento.

Uno de los indicadores de calidad es la investigación, la cual se debe hacer profesionalmente en estas casas de estudio y esa es la dificultad que presentan algunas universidades, dado que la investigación es escasa, por ello la condición $\mathrm{N}^{\circ}$ 4 de las políticas básicas de calidad pide: "Que la universidad tenga políticas que fomenten el desarrollo de la investigación, los proyectos de investigación aprobados con presupuesto, equipamiento y personal, deben tener un código de ética, docentes que se dediquen a la investigación y se debe tener el registro de proyectos de investigaciones", Sunedu (2019).

Ante esto hay que resaltar que el código de ética refiere que el alumno o docente investigador debe ser consciente que al momento de iniciar su proyecto debe respetar la autenticidad y aportes de otros investigadores, razón por la cual las universidades deben tener un grupo de docentes que se dediquen exclusivamente a la investigación y en ese sentido nuestro país ha empezado a mejorar gracias a esta exigencia muy necesaria y acertada de la Sunedu.

La revista In Crescendo reúne los aportes de muchos investigadores nacionales y extranjeros, quienes con sus artículos muestran las investigaciones que vienen realizando.

Nuestra revista fomenta la investigación, apoya a muchos docentes universitarios que desean publicar sus trabajos con fines de certificación para estar incluidos en los repositorios digitales que permitan difundir sus trabajos y se identifican con las políticas de gobierno de nuestro país.

Dra. Mónica Patricia Arias Muñoz

EDITORA ASOCIADA - REVISTA IN CRESCENDO 